Claremont Colleges

Scholarship@ Claremont

All HMC Faculty Publications and Research

HMC Faculty Scholarship

$11-1-2008$

\title{
Mathematics in the Mountains: The Park City Mathematics Institute
}

Andrew J. Bernoff

Harvey Mudd College

\section{Recommended Citation}

A. J. Bernoff, Mathematics in the Mountains: The Park City Math Institute," Math Horizons XVII (November 2008) 20-21.

This Article is brought to you for free and open access by the HMC Faculty Scholarship at Scholarship @ Claremont. It has been accepted for inclusion in All HMC Faculty Publications and Research by an authorized administrator of Scholarship @ Claremont. For more information, please contact scholarship@cuc.claremont.edu. 
"The Undergraduate Summer School is an extraordinary opportunity. It provices students with a broad overview of a subject and introduces them to the wider mathematical community."

\section{Mathematics in the Mountains: The Park City Mathematics Institute}

Andrew J. Bernoff

Harvey Mudd College

t's noon. A Fields medalist, master high school teachers from the US and abroad, aspiring undergraduate and graduate students, gifted expositors of mathematics, and mathematical artists gather at tables under a tent. Lunch and so much more is served at these meetings of the minds.

This cross-pollination of mathematicians from many walks of life is the hallmark of the Park City Mathematics Institute (PCMI). "One of the great things about PCMI is that it gives participants opportunities to interact with people from different parts of the mathematical community," enthused Professor Jessica Sidman of Mt. Holyoke College, who was one of the undergraduate lecturers this year, "I wish I had known about it when I was an undergraduate. Coming from a small liberal arts college, I essentially didn't have substantive interactions with graduate students until I became one!" Each summer since 1994 the Institute for Advanced Study in Princeton has sponsored this unique mathematics event in Park City, Utah. For three weeks mathematics researchers, scholars, undergraduate and graduate students, as well as mathematics educators at the secondary level, gather for research, study, and diversions (mathematical and otherwise) in Park City, a setting of breathtaking mountain scenery and outdoor opportunities. The program is supported by the National Science Foundation, the National Security Agency and a host of smaller public and private grants.

Every year PCMI has a theme; this past year it was Analytic and Algebraic Geometry: Common Problems Different Methods. The undergraduate program had a threeweek long lecture course by David Perkinson of Reed College on algebraic geometry designed to be accessible to rising sophomores. "The Undergraduate Summer School is an extraordinary opportunity. It provides students with a broad overview of a subject and introduces them to the wider mathematical community," commented Perkinson."After seeing this program firsthand, I will routinely encourage our students to attend." In addition, three one-week seminars on topics in algebraic

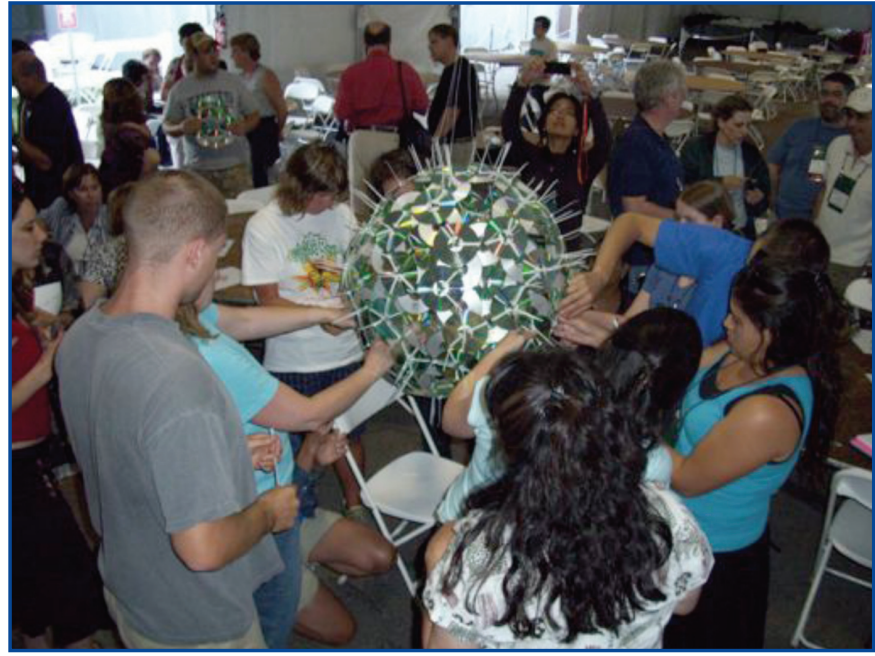

PCMI participants put the finishing touches on a truncated icsosahedron assembled out of CDs and cable ties. Noted mathematical sculptor George Hart designed and supervised the exercise.

geometry ran simultaneously. The coursework is intense, but there is very much a team spirit among the students. "PCMI is amazing because it provides ample opportunity to learn both in and outside of class," said Rebekah Tjostolvson, a sophomore at the University of Portland, "They offer such a wide variety of classes, have problem sessions and some of the professors even make themselves available during their downtime. I really like how they recognize that we need some fun and relaxation and encourage that as well."

Another thread in the PCMI tapestry is the Undergraduate Faculty Program (UFP) which focuses on collegiate mathematicians with a strong interest in undergraduate education. The UFP offers opportunities for broad professional growth and engagement with the excitement of mathematics by working with peers on new approaches to teaching, tackling research questions, and interacting with the broader mathe- 
matical community. This year's UFP instructor/coordinator was Thomas Garrity from Williams College. The centerpiece of the UFP this year was a lecture course on algebraic geometry, but every lecture was followed by a discussion of teaching techniques. The participants of the UFP are also producing a manuscript on Problems in Algebraic Geometry which they hope to publish. Perhaps more importantly, several of the UFP faculty plan to teach seminars in algebraic geometry in this academic year, buoyed by the support of their fellow participants. "I gained a lot from networking with peers at other undergraduate institutions," said Shawn Robinson an Assistant Professor at the University of Maine at Presque Isle. "We shared ideas on practical matters ranging from productive use of class meetings to conducting effective hiring searches, and we began a professional collaboration that I'm sure will prove to be productive."

Part of the glue that holds the various programs together is a broad variety of cross-program activities. One favorite is "Pizza \& Problem Solving" - based on the problem solving seminar they run at Harvey Mudd College, Andrew Bernoff and Francis Su choose a topic such as "Hidden Symmetries" or "Lattice Points and Polynomials" and give a quick introduction to the area. Students, professors and teachers then work on the problems collaboratively while munching on pizza. Participants present their solutions to the collective resulting in lively discussion.

Another crossprogram activity this year featured More information about PCMI can be found at: pcmi . ias . edu/index . php. The deadline for next year's program is January 28, 2009. The program accepts students and faculty from a diverse group of institutions and backgrounds, and all are encouraged to apply. Problem Solving seminar.

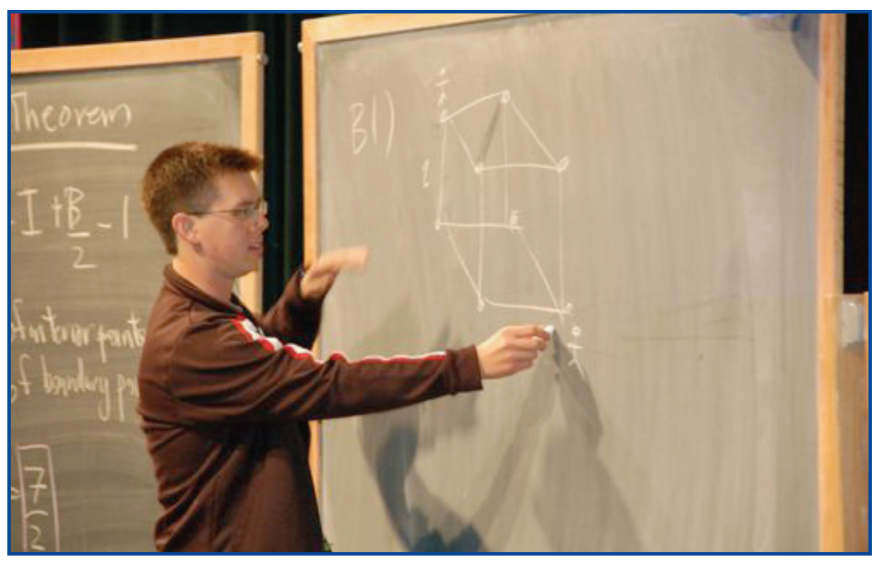

Parousia Rockstroh who graduated from Harvey Mudd College this past spring shows how to find the shortest path along the surface of a cube connecting antipodal vertices during PCMI's Pizza and

For amusement there are both low-key and high-energy diversions for students. The PCMI film festival this year featured showings of Flatland, an animated look at life in the plane; Hard Problems, a documentary about the International Mathematics Olympiad, and perhaps the crowd favorite, The Great Pi/e Debate with a transcendental introduction by Tom Garrity. Wednesday afternoons and weekends are left mathematical sculptor George Hart of SUNY Stony Brook who gave a slide show of his polyhedron-inspired mathematical sculptures that vary in size from a few inches to a few yards. Hart's construction and installations hang prominently in many universities across the country. After the lecture, Hart led a hands-on construction of a truncated icosahedron made from CD's and cable ties, the results of which adorned the lunch tent for the remainder of the session. In a related activity, the secondary school teachers taught participants how to construct a menagerie of polyhedra using origami or Zome tools, the mathematical equivalent of an erector set.

Another mainstay of the program is the Clay Lectures in which experts sketch an overview of the area of concentration, but at a level accessible to all the attendees. Having a Field's medalist describe the state of knowledge in algebraic geometry is both daunting and exhilarating. unstructured, and participants organize games of ultimate Frisbee and outings to local attractions such as chair lift rides to the top of the local mountain, or dry bobsled runs at the nearby 2002 Olympic Park for those in search of an adrenalin rush. Weekend trips to explore the spectacular Utah outdoors, such as Arches National Monument and the Great Salt Lake are common. Everybody comes back with some fond memories, new friends, and hopefully feeling mathematically rejuvenated.

Next year's session promises to be equally engaging; the topic The Arithmetic of L-functions is an area of rapid development. Undergraduates will learn analytic number theory, the origins of the prime number theorem, and the connection to the Riemann hypothesis.

Come join us!! I promise you that not only will it be fun, but you also will learn some fascinating mathematics. 